\title{
Representations of mental health and arts participation in the national and local British press, 2007-2015
}

\author{
Atanasova, D., Koteyko, N., Brown, B. \& Crawford, P.
}

\begin{abstract}
We analysed news articles published in national and local British newspapers between 2007 and 2015 to understand 1) how mental health and arts participation were framed and 2) how the relationships between participants in arts initiatives were conceptualised. Using corpus-assisted qualitative frame analysis, we identified frames of recovery, stigma and economy. The recovery frame, which emphasised that mental illness can be treated similarly to physical illness, positioned arts participation as a form of therapy that can complement or substitute medication. The stigma frame presented arts participation as a mechanism for challenging social conceptions that mentally ill individuals are incapable of productive work. The economy frame discussed the economic burden of mentally ill individuals and portrayed arts participation as facilitating their return to employment. Using thematic analysis, which paid attention to the representation of social actors, we found that service users were identified as the prime beneficiaries of arts initiatives and arts participation was conceptualised as a way to bring people with mental health issues together. We discuss these findings against existing research on media representations of mental health and the concept of 'mutual recovery' and suggest what wider concurrent developments in the areas of mental health and the media may account for the uncovered frames and themes.
\end{abstract}

Keywords mental health; recovery; stigma; framing; arts

\section{Introduction}

The news media are believed to play a significant role as actors in the public sphere and policy process (Soroka et al., 2013). Where health is concerned, some authors go so far as to say that the media, and newspapers in particular, can have a key role in forming perceptions of health and illness in general (Lupton, 1999) and of mental health in particular (Thornton \& Wahl, 1996). This is despite the rise of social media where individuals can actively seek out health information (Kelly et al., 2010). Media portrayals of mental health have therefore received substantial attention over the years, but much research has focused on representations of specific diagnoses (e.g., van Gorp \& Vercruysse, 2012) or on events involving mentally ill individuals (e.g., Blood \& Holland, 2004). Such studies consistently identify themes of dangerousness involving the representation of mentally ill individuals as a risk to society (Klin \& Lemish, 2008). In comparison, representations of mental health and arts participation have not, to our best knowledge, been studied - despite the fact that the link between arts participation and (mental) health has been receiving growing attention, especially in Britain.

As an Arts Council England evidence review acknowledges, there exists a longstanding consensus about the value of arts to society - life without the arts would be 'static and sterile' (p. 4). But arts participation also has a role outside of this intrinsic merit of illuminating our inner lives and enriching our emotional worlds (Arts Council England, 2014). Since the 1960s, artists and arts organisations in Britain have been delivering projects in hospitals, prisons and in the streets - benefiting excluded social actors and groups, while also deriving value for their creative work (Aitken, 2008). In the recent years, our understanding about the potential of the arts to 
contribute to (mental) health and wellbeing has increased, as several evidence reviews have demonstrated that: individuals who attend cultural places are more likely to report good health in comparison to those who do not; higher frequency of engagement with the arts is associated with higher life satisfaction; applied arts interventions have a positive impact on specific mental health conditions such as dementia and depression; and arts participation can achieve positive outcomes for patients and staff alike (e.g., Arts Council England, 2014; Staricoff, 2004).

This growing appreciation for the role of the arts in (mental) health and wellbeing and the exponential growth of the 'arts in health' field has been aided by an evolving understanding of health. Particularly, there has been a significant shift in understanding the determinants of health - a highly contested 1970s proposition that health services have only a small impact on overall health status (McKeown, 1976) has now become part of mainstream thinking (Aitken, 2008). As health has begun to be understood in a broader sense, it has also become widely agreed that economic and social factors such as income inequality, education level and social relationships affect health (Aitken, 2008) and these factors can, in turn, be affected by arts participation, particularly when it comes to social relationships (Brown, 2015). Arts participation, it has been argued, may serve to make social relations between service users, informal carers and mental health professionals more egalitarian (Brown, 2015). We therefore argue, against this background, that it is timely to explore how mental health and arts participation have been presented in the British press and ask:

- How are the creative initiatives engaging mental health users framed? (RQ1)

- How are the relationships between participants in arts initiatives conceptualised? (RQ2)

\section{Conceptual framework}

The origins of frames as concepts for understanding representations can be traced to Bartlett's (1932) classic work in psychology. Having migrated into other disciplines, frames and frame analysis are now considered a 'fertile' area in media and communication research (Riffe, 2004, p. 2) and in research into the social representation of health and illness (e.g., Stefanik-Sidener, 2013). Frame analysis is also gaining ground in studies of media representations of mental illness (Klin \& Lemish, 2008), particularly regarding the frames used to understand violence in relation to mental illness (e.g., Johnson \& Miller, 2016; Olufowote \& Matusitz, 2016).

Understood as central organising ideas or story lines (Gamson \& Modigliani, 1989), frames simplify complex events and issues by emphasising some aspects at the expense of others. In this view, '[the] conventions media producers use to organize, make sense of, and give meaning to social phenomena have symbolic power to assert the narratives of certain privileged and dominant perspectives' (Johnson \& Miller, 2016, p. 212). Thus, frames promoted in news articles may, arguably, increase the likelihood of audiences interpreting events and issues in particular ways (Chong \& Druckman, 2007). Put simply, framing is a way 'to select some aspects of a perceived reality and make them more salient in a communicating text, in such a way as to promote a particular problem definition, causal interpretation, moral evaluation, and/or treatment recommendation' (Entman, 1993, p. 52).

Indeed, the long history of framing research has also resulted in various methodological approaches to frame identification and analysis categorised as deductive and inductive (Matthes, 2009). While deductive approaches are an efficient way of scrutinising media texts against frames identified in past research, they risk omitting newly emerging frames. This shortcoming is addressed by inductive approaches where grounded analysis is used to identify frames (e.g., Gamson, 1992), but such approaches suffer from a degree of subjectivity. Here subjectivity can 
refer to 1) the subjective involvement of researchers and specifically, how qualitative frame identification may be impacted by the preconceptions that researchers often unconsciously bring to the analysis or 2) the vague terms in which qualitative researchers describe the steps that had led to the identified frames (van Gorp, 2010).

The corpus-assisted frame analysis approach (see Touri \& Koteyko, 2015) promises to address such subjectivity by commencing with a data-driven stage using corpus-linguistics techniques (which can limit the effects of researcher involvement) and proceeding with a systematic approach to qualitative frame identification (in which the steps of analysis are explicitly stated) (see van, Gorp, 2007). Corpus linguistics relies on the automatic processing of large electronically available text collections (referred to as corpora) to explore questions around the meaning and use of specific words and word combinations and the study of media content is among the fastest growing areas where corpus linguistic techniques have been applied (Baker, Gabrielatos, \& McEnery, 2013), leading to corpus-assisted studies covering a wide range of topics including health (Crawford et al., 2008).

This corpus-assisted approach referred to above and adopted here follows the suggestion that frames can be detected via keywords indicative of the conscious and unconscious evaluations that journalists make when creating news stories (Entman, 1993). The definition of framing as being about selection and salience (Entman, 1993), where salience can mean that by repeating certain terms, concepts and words certain ideas about events and issues are foregrounded and others hidden, maps well onto the concept of keywords in corpus-linguistics. In corpus-linguistics, keywords are words that are significantly more frequent in a corpus in comparison with another corpus (according to log-likelihood or Chi-square tests) (Baker, Gabrielatos, \& McEnery, 2013). Such keywords can be seen as traces of core propositions (e.g., about the causes and solutions of a problem) that form part of a frame (Touri \& Koteyko, 2015). Once keywords have been identified, these core propositions can be further explored by analysing the immediate textual context of keywords (referred to as keyword concordances) (Sinclair, 1991) in order to identify the full range of framing and reasoning devices that form part of a frame.

\section{Methodology}

UK news articles were collected from Nexis using 'mental health', 'mental illness' or 'mental wellbeing' as exact phrases in combination with 'art' . To ensure that news articles focused on mental health instead of just mentioning the term, we added the subject areas 'mental health' and 'mental illness' (strong references only) to our search query. Initial searches showed that the volume of coverage significantly increases in 2007 - a year of key legislative changes in the area of mental health such as the 2007 Mental Health Act which amended the 1983 edition (legislation.gov.uk, 2007). Consequently, this is the starting point of our analysis with a cut-off in 2015 - the closest full year at the time of data collection. To arrive at the final corpus of 1,412 newspaper articles, we excluded duplicates and newswires. While media analysis studies typically focus on national newspapers due to their agenda-setting function (McCombs \& Shaw, 1972), we retained local newspapers in the final sample, as arts initiatives were more frequently featured in the local than the national press (1,073 and 339 news articles, respectively). This inclusion of local newspapers represents another novel aspect of our research in addition to the thematic focus on mental health and arts participation.

\footnotetext{
1 'Art' aside, all keywords were informed by our literature review.
} 
We started our corpus-assisted frame analysis (answering RQ1 - how the creative initiatives engaging mental health users are framed) by generating a keyword list (see Table 1). This list was produced using WordSmith Tools (Scott, 2016) by comparing our corpus of 1,412 news articles (485,186 words) with a reference corpus of 100 million words of written and spoken British English (BNC, 2009). To identify frames (and the frequency with which they were used), we relied on 1) grouping the first 100 keywords $^{2}$ into semantic sets or word groups of closely related meaning (see Duguid, 2010; Touri \& Koteyko, 2015) and 2) qualitatively analysing the extended concordances ${ }^{3}$ of these first 100 keywords following van Gorp's (2007) systematic approach to qualitative frame identification. Grouping keywords into semantic sets is a 'process, in which generalisations about overall patterns in the data are reached by identifying shared attributes - characterising words as similar or related' (Duguid, 2010, p. 115) and it involves 'shunting back and forth' (Duguid, 2010, p. 114) between keyword lists and concordance lines. Following this process, we identified the semantic sets: 'activism' (keywords included AWARENESS, RAISE); 'art' (e.g., MUSIC, EXHIBITION); 'institutions and infrastructure' (e.g., WORKSHOP, COUNCIL); 'medicine' (e.g., DISORDER, PATIENT); 'relationships' (e.g., COMMUNITY, GROUP); and 'other' (keywords that cannot be readily classified into a theme e.g., PLACE, OPEN).

[Table 1 should appear about here]

As one semantic set (the 'relationships' semantic set) focused on relational aspects of mental health and arts initiatives, we created a sub-corpus of news articles mentioning any of the keywords within this set (CARERS, COMMUNITY, FAMILY, GROUP and SUPPORT) in the context of the search terms 'mental health' and 'art'. We used this sub-corpus of 515 newspaper articles to explore how the relationships between participants in arts initiatives were conceptualised (RQ2). In doing so we followed existing guidelines for conducting thematic analysis (Braun \& Clarke, 2006), while paying attention to how social actors are represented (van Leeuwen, 2008) and particularly, which social actors were identified as prime beneficiaries of arts initiatives (e.g., service users, informal carers or mental health professionals).

\section{Results}

Our corpus-assisted frame analysis of the total sample of 1,412 news articles identified three frames (see Table $2^{4}$ for an overview), of which recovery was the most prominent, closely followed by stigma and finally, economy. Our thematic analysis of the sub-set of 515 news articles from the 'relationships' semantic set distinguished two themes - arts participation benefits service users and arts participation brings people with mental health issues together. We begin our presentation of these findings with a description of the frames of mental health and arts participation supported by indicative direct quotes. We then present our findings regarding how the relationships between participants in arts initiatives were conceptualised.

\footnotetext{
${ }^{2}$ Focusing on the top 100 keywords is an established practice in corpus linguistics, which affords a 'representative overview' without being overwhelming to the reader (Baker, Gabrielatos, \& McEnery, 2013, p. 72).

${ }^{3}$ Extended concordances were composed of the sentence containing the keyword, two sentences before and two after.

${ }^{4}$ This table provides an overview of the three frames composed of a problem definition, causes and consequences of the problem as defined, solutions and moral evaluations - a presentation format that follows existing conventions (e.g., Atanasova \& Koteyko, 2016; van Gorp \& Vercruysse, 2012).
} 
[Table 2 should appear about here]

\section{Recovery}

In the recovery frame, which emphasised that mental illness can be treated and cured just like physical illness, arts participation was positioned as a complement or even an alternative to medication and an overall successful form of therapy. News articles featured: former mental health ward inpatients saying ' $[\mathrm{m}]$ usic is my passion and I believe it definitely enhanced my recovery' (Leicester Mercury, 18/09/14); and service users discussing how they could 'conquer depression through the power of art' (Derbyshire Times, 15/02/13). By recounting success stories of how 'pursuing artistic skills' allowed sufferers from 'a grey cloud of depression' to 'add colour back' into their lives (East Anglian Daily Times, 06/10/12) and of individuals successfully 'combating' mental illness through 'the healing power of creativity' (Liverpool Echo, 16/10/14), news articles suggested that arts participation can aid getting back to a pre-illness, mentally healthy state and painted an image of recovery as an individual, solitary combat.

The overall message regarding mental illness was that, as a service user put it, '[i]t's as if you were to break your leg and not treat it, but instead of a limb, it's your mind that's broken and it needs treatment' (Croydon Advertiser Series, 25/12/14) and arts participation is a suitable form of therapy - in the words of a post-traumatic stress disorder sufferer, '[w]e know it works. Art and creative writing, such as poetry, is being increasingly used as a therapy' (Express and Echo, 09/05/13). News articles also pointed out that medication 'can be combined with other helpful rehabilitation, such as exercise and art, to help recovery' (Aberdeen Press and Journal, 25/01/13) or argued that art is a way of preventing mental health problems 'without using medication' (Manchester Evening News, 23/01/13). Suggestions were made to train care workers 'in pioneering techniques using creative arts' (Evening Chronicle, 03/04/13) and to offer (more) social prescribing schemes ${ }^{5}$ featuring arts and creative practice, as patient feedback 'has been extremely positive' (The Journal, 25/03/13). Thus, arts participation appeared to be integrated with the medical model of mental illness, which focuses on the physical or biological causes of mental illness and consequently, on individual adjustments and rehabilitation efforts rather than the wider socioeconomic and environmental factors that may impact mental health and aid recovery (Blaney, 2015).

\section{Stigma}

The stigma frame presented mental illness as '[t]he last taboo' and argued that 'when you have a mental illness, it doesn't mean you can't achieve things' (Derby Evening Telegraph, 19/04/12), while also emphasising the discrimination and social exclusion that mentally ill individuals still face. In this context, arts initiatives were presented as a means 'to challenge the stigma around mental health issues' (The Plymouth Herald, 05/04/12) and more generally raise awareness. Stigma was traced to: the entertainment industry and its use of terms associated with mental illness stereotypes as in the case of 'Farmaggedon's "Psychosis", a house themed around clowns wielding chainsaws' (Liverpool Echo, 01/11/14); '[i]gnorance and superstition' (The Guardian, 23/12/14); and the combined effect of 'misinformation' attached to mental illness (Bath Chronicle, 11/07/13) and lack of information - 'people don't know any better. If no one around them is talking about

\footnotetext{
${ }^{5}$ Social prescribing schemes are 'a mechanism for linking patients with non-medical sources of support within the community’ (CentreForum Mental Health Commission, 2014).
} 
mental health, and it's something that's "hushed up" all the time, where are they going to learn' (The Western Mail, 24/02/14).

News articles expressed concerns that ' $[\mathrm{t}]$ he stigma attached to mental health problems in some communities - for example African-Caribbean, African and South Asian - prevents people from accessing services at an early stage' (Leicester Mercury, 09/10/14). It was also feared that stigma may lead to decreased support for mental health services, as '[t]he long shadow of Victorian-era horror at any sign of mental illness still lingers, sustaining stigma and inhibiting funding for services' (The Guardian, 23/12/14). Societal views towards mental illness were thus criticised - '[b]oth friends and family can be intolerant or else ignorant of mental health problems' (Manchester Evening News, 10/10/15). This overall focus on ordinary people (communities, friends, family) as the prime source of stigma is consistent with a long-observed tendency to focus on individual-level rather than institutional and structural stigma in the context of mental health (Corrigan, Markowitz, \& Watson, 2004).

\section{Economy}

The economy frame focused on the rising cost of mental illness as a result of: higher demand for mental health provision with which '[n] either the NHS nor overstretched social services can keep up' (The Times, 22/01/14); productivity lost to mental health problems - '[m]ental health problems cost the country an estimated $£ 100$ bn each year through lost working days and benefits' (The Guardian, 28/10/14); and welfare claims by mentally ill individuals - 'in this region, over 10,000 people claim Employment Support Allowance (ESA) and have a mental health condition' (The Journal, 17/12/14). Against this background, arts participation was positioned as facilitating return to employment and a means for prevention of mental illness. Describing a mentoring scheme that partnered professional artists with a group of mentally ill individuals, an article stated that the aim of the initiative was 'to build confidence and help the group towards employment' (The Journal, 13/10/15). Elsewhere, a consultant argued that encouraging children 'to play and draw to identify what is causing their anxiety or stress' can contribute to 'better prevention earlier (...) and we would see fewer children needing NHS care' (Daily Mirror, 10/02/14).

\section{Relationships between arts participants}

In the analysed news articles, relationships between arts participants were conceptualised exclusively in terms of arts participation brings people with mental health issues together. Thus, an arts initiative was described as one that 'brings together people from all walks of life who are struggling with similar things such as depression and anxiety' (Western Gazette Series, 09/08/12). Elsewhere, a charity offering art, craft, literacy and creative writing classes was said to provide a place where 'mentally ill people do not feel judged or isolated' (North Somerset Times, 28/03/12). People suffering from mental health issues were also invited to join wellbeing groups 'set up for those who are isolated in their community to come together and do some arts and crafts' (Nuneaton News, 07/08/14). As our analysis additionally paid attention to social actors (e.g., service users, informal carers, mental health professionals) identified as prime beneficiaries of arts initiatives, we distinguished the theme arts participation benefits service users. Notably, benefits to service users appeared to be often elaborated by service managers, as in 'workshops include horticulture, conservation, pottery, jewellery making, arts and crafts and music (...) We empower our users to learn new skills to help them become more independent' (Leek Post and Times, 09/07/14).

\section{Discussion}


We combined software-driven statistical analysis with qualitative examination of context to identify 1) frames of mental health and arts participation (and frequency of frame use) and 2) conceptualisations of participants in arts initiatives in a large news article sample spanning almost a decade (2007-2015). In this final section, we compare our findings against existing research on media representations of mental health, discuss key findings against the emergent concept of 'mutual recovery' (Brown, 2015, 2016; Crawford et al., 2013) and look for explanations for the uncovered frames and themes in wider contemporaneous developments in the areas of mental health and the media. We conclude with a summary of key findings, limitations and future research directions.

The recovery frame is, indeed, not without precedents in analyses of mental health representations in the media, but ours is among the few studies which described in detail what it entailed and identified recovery messages as the most prominent in the analysed sample. The earliest mention of a 'treatment and recovery' theme can be traced to research by Corrigan and colleagues (2005), who concluded that this was the second most frequently occurring theme in their analysis of selected newspapers from the United States (US) (present in 26\% of all analysed news articles). It comprised the subthemes 'research advances', 'biological treatments', 'psychosocial treatments' and 'recovery as a reasonable outcome' with the latter subtheme present in only $4 \%$ of all analysed news articles. Corrigan and colleagues (2005) speculated that this might have been due to the novelty of the concept of recovery motivating journalists to only gradually start introducing it by anchoring it in more familiar themes of biological and psychosocial treatments. Yet, a more recent study of US news coverage found that the topic of 'successful treatment for or recovery from mental illness' was still the least frequently occurring topic (present in 14\% of all analysed news articles) (McGinty et al., 2016). Other studies that identify recovery messages include those by: Whitley, Adeponle, \& Miller (2015) who found that the 'recovery' theme (which included discussions about recovery or rehabilitation of an individual or in general) was the least discussed in selected Canadian newspapers (found in $24.8 \%$ of all analysed news articles); and Whitley \& Berry (2013) who concluded that the theme of 'recovery or rehabilitation' was only present in $18 \%$ of all analysed news articles from selected Canadian newspapers. Overall, these authors have provided little context beyond percentages as to what precisely these recoveryrelated themes or topics entailed.

The prominence of the recovery frame in our sample could be attributed to a combination of factors. These include the growing momentum of the recovery-based movement in the UK and the increasing emphasis on recovery in UK policy at largely the same time as the publication of the analysed here news articles. The core message of this recovery-based movement has been that people with mental health issues have the right to support in order to recover their lives, even if their mental health problems cannot be resolved completely (Crawford et al., 2013). Facilitated by a perceived crisis in UK mental health care (in terms of e.g., shortage of beds and use of compulsion in mental health services), growing interest in self-help more generally and limited evidence for the effectiveness of pharmaceutical, genetic and neuroscientific interventions (Crawford et al., 2013), the recovery movement has gained ground and its core ideas have become increasingly central to UK policy and service delivery (e.g., Department of Health, 2001, 2011).

Another factor that could help account for the prominent position of the recovery frame is the voices that were included in the analysed news articles. As many of the indicative direct quotes used to describe the recovery frame show, messages about recovery through arts participation often came from individuals directly affected by mental health problems. It has been recognised for a long time that the voices of mental illness sufferers have been underrepresented in media content 
and it has been argued that, had they been given more opportunities to speak, their representation as dangerous, violent and unpredictable would have been less widespread (e.g., Whitley \& Berry, 2013). This also conveys a need to treat news articles as polyphonic (containing various voices) (Calsamiglia \& López Ferrero, 2003; Montgomery, 2007) - which was beyond the scope of this study and, as we argue in our concluding remarks, is a welcome direction for future research.

Additionally, wider concurrent developments in how newsworthiness is understood, particularly the growing emphasis on 'good news' as a criterion for news selection, could also have contributed to the widespread use of the recovery frame. As a journalistic news value, which motivates news selection, 'good news' has long been considered a weaker selection criterion than 'bad news' (Harcup \& O’Neill, 2016). Recent trends in journalism however challenge this view. Proponents of 'constructive' journalism have called for more 'good news' in response to society's changing relationship with news (with the growth of social networking sites as a means of news consumption, demand for 'good news' has been rising) (Beckett, 2015), but also in response to concerns that news reporting has reached 'peak negativity' (Taibi, 2015), turning people away from news and instigating a sense of disempowerment and resultant inaction on important events and issues (Baden, 2015).

Finally, the prominence of the recovery frame could also be attributed to the nature of our sample and specifically, the inclusion of local newspapers. Contrary to national media, local newspapers cater to smaller communities. It is therefore reasonable to assume that the readers, and indeed, writers of news articles published in local newspapers may personally know the individuals involved in the reported stories, resulting in more positive writing. This hypothesis is supported by the dynamics of, for example, sports reporting in local media, particularly expectations that local sports journalists should 'contribute to the team effort' by giving local teams 'positive feedback' regardless of the game outcome (Rowe, 2005, p. 133).

Whatever the reasons for the prominent position of the recovery frame, this finding is an overall positive development - much research has consistently indicated that most people suffering from mental health problems do make a complete or partial recovery (Childers \& Harding, 1990; Whitley \& Drake, 2010) and it is therefore good news that news articles reflect this. At the same time, we also wish to draw attention to the markedly medicalised, narrow and individualised conceptualisation of recovery that this frame offered.

The recovery frame was complete with physical health analogies, meaning that, in large part, the medical model of mental illness (Blaney, 2015) remained unperturbed. Such a view of mental health problems as akin to physical illnesses may facilitate their continued medicalisation (Conrad, 2005; Hofmann, 2016), while also encouraging narrow, unrealistic expectations about recovery - in the analysed material, recovery was understood as getting back to a pre-illness, mentally healthy state (e.g., 'adding colour back') rather than getting rid of or living with the symptoms. Views of recovery as being strictly about getting better have been criticised by service users, carers and mental health professionals alike as too reductive (Lewis et al., 2016). The way in which recovery was conceptualised here was thus in the conventional sense of return to a normal state of health, mind, or strength, which is different from the way in which the recovery movement has conceptualised it - as 'a way of living a satisfying, hopeful, and contributing life even within the limitations caused by illness' (Anthony, 1993, p. 15); a sense of wellbeing regardless of symptoms (Davidson et al., 2006); a way of life or attitude involving the growth of new meaning and purpose beyond the effects of mental illness (Deegan, 2003).

Also absent from the recovery frame was any suggestion of a more social model of how mental health symptoms might be occasioned and sustained. Recovery was constructed in terms 
of personal struggle (e.g., 'combating', 'conquering'), but recovery as the heroic journey of individuals is a rather narrow view, given that the capacity to recover may often be relational, requiring a mix of personal, social and economic resources - from housing to connections and friendships (Jacobson \& Greenley, 2001; Tew, 2013). This medicalised and individualised framing of recovery is, however, compatible with wider trends in the ways in which various health and health-related issues from sleep to obesity have been framed (Meadows, 2008; Ortiz et al., 2016).

In the wider literature about policy and practice where recovery is concerned, there is an emerging critique of the individual focus of many recovery initiatives (Harper \& Speed, 2012) as well as the difficulty in integrating recovery approaches in training for health professionals (Stickley et al., 2016), the lack of recognition of power differences (Stacey et al., 2016) and the gap between policy as inscribed in official documents and how mental health practice is enacted and embodied (Smith-Merry \& Gillespie 2016). Overriding policy concerns of cost containment and social control over individuals identified as having mental disorders (Scheid, 2016) may supervene over therapeutic considerations. Thus, the practice of recovery interventions may well involve a continued focus on symptom remission and medication compliance at the expense of personal choices (Jacob et al., in press). The egalitarian ambitions of many recovery programmes are in tension with continuing patterns of discrimination in treatment provision (Holley et al., 2016). As yet, these kinds of critiques of recovery policies and the limitations of practice have not been reflected in the news media.

A further distinctive feature of the data described here was how stigma was engaged with. Whilst many existing studies have highlighted evidence of stigmatising reporting (Klin \& Lemish, 2008), here stigma was discussed as an undesirable phenomenon that needs to be combatted. By framing stigma in this way, the media we analysed can be said to be to a greater extent part of the solution than of the problem. We would still argue that this welcome engagement with stigma can be further improved by accounting for the institutional and structural sources of stigma. Similarly to much policy and professional discourse, stigma was always seen in the analysed news articles as coming from ordinary people or society as a whole (communities, friends, family). Professional and policymaking actors were not identified as sources of stigma despite many academic writers drawing attention to the persistent negative representations of people with mental health problems as risky and having limited potential in professional and policy discourse (e.g., Chamberlain, 2016) and reports of service users suffering discriminatory treatment in therapeutic programmes (Holley et al., 2016).

Finally, the economy frame, which was the least frequently used frame in our sample is largely consistent with the focus on spending and the economic impact of mental health service provision in contemporaneous policy documents (e.g., Department of Health, 2009, 2011). Use of the economy frame in the analysed news articles may have also been stimulated by the global financial crisis of 2007-2011 (Elliott, 2011), which may have contributed to the more prominent position of financial considerations. By focusing on benefits claims by mentally ill individuals and positioning arts participation as key for their transition from welfare to work, this frame focused on minimising demands on existing services. News articles did not discuss the non-financial, wider wellbeing effects of return to work and arts participation and thus, seemed to imply that recovery is about getting service users on board with the neoliberal agenda (the idea that individuals' main goal should be to lead economically productive lives) (Glasgow, 2012). This positioning of arts participation as making economic sense can, however, be seen as good news for the arts sector in the light of austerity cuts and perceptions of the arts as 'non-essential' (Miller, 2016; Pountney, 2015). 
Our reflections on how relationships between participants in arts initiatives were conceptualised and the two themes we uncovered - arts participation benefits service users and arts participation brings people with mental health issues together - are informed by the emergent concept of 'mutual recovery' (Brown 2015, 2016; Crawford et al., 2013). 'Mutual recovery' scholarship highlights the often-overlooked needs of hard-pressed informal carers and mental health professionals who might also need to recover from the stress of their daily work (e.g., Pinquart \& Sörensen, 2003). If the concept of recovery focuses on the needs of service users, 'mutual recovery' widens the focus towards informal carers and mental health professionals and argues that arts participation can bring together and aid the recovery of the full range of social actors within the mental health area.

The two themes that we described - arts participation benefits service users and arts participation brings people with mental health issues together - therefore reflect Brown's (2016) contention that full-fledged mutuality between providers and clients remains elusive. As some of the quoted excerpts demonstrate (e.g., an initiative that 'brings together people from all walks of life who are struggling with similar things such as depression and anxiety' or inviting people with mental health issues to join wellbeing groups 'set up for those who are isolated in their community to come together and do some arts and crafts'), divisions between service users, informal carers and mental health professionals persist. The focus in the analysed news articles was on service users and their segregated recovery through arts participation - service users were recovering 'together', but together with other service users, not alongside informal carers or mental health professionals. Thus, the potential of creative practice to advance a more mutual model of recovery was underdeveloped in the analysed news articles.

In conclusion, our study has contributed to better understanding 1) how mental health and arts participation were framed and 2) how the relationships between participants in arts initiatives were conceptualised in the British press throughout nearly a decade. We consider the widespread use of the recovery frame an overall positive development which recognises the reality that many people who experience mental health problems do recover. At the same time, we are concerned about the medicalised, individualised and narrow conceptualisation of recovery that this frame offered. A further distinctive and positive finding was how stigma was engaged with - stereotypes and discrimination were discussed as problems that need combating; news articles did not present mentally ill individuals in stigmatising ways. We wish, however, that news articles had also acknowledged the structural and institutional sources of stigma. We also argue that, with its focus on the role of the arts in helping the transition of mentally ill benefits claimants from welfare to work, the economy frame seemed to imply that recovery is about getting service users on board with the neoliberal agenda. And yet, we recognise that positioning arts participation in this way could be beneficial from the viewpoint of arguing against further funding cuts for the creative industries. Finally, we found that despite evidence that arts participation can contribute to the recovery of the whole range of social actors in the area of mental health (service users, informal carers and mental health professionals), this mutual aspect was underdeveloped in the analysed data. Despite these contributions, two particular limitations also emerge relating to our focus on print newspapers and the need to approach news articles as polyphonic. Seeing how our analysis was enriched by expanding the range of print newspapers to include local in addition to national ones (in terms of the elucidation of the recovery frame, which mostly emerged through local titles), we advocate for future research to further widen the range of studied media types. We also argue for future systematic analyses of voice in media content, as whose point of view is foregrounded may assist us to better understand why the media cover mental health issues in certain ways. 
Acknowledgements This work was supported by the Arts and Humanities Research Council [grant number AH/K003364/1].

\section{References}

Aitken H (2008) Catalysing arts and health. Edinburgh: Scottish Arts Council.

Anthony WA (1993) Recovery from mental illness: The guiding vision of the mental health service system in the 1990's. Psychosocial Rehabilitation Journal 16(4), 11-23.

Arts Council England (2014) The value of arts and culture to people and society: An evidence review. Manchester: Arts Council England.

Atanasova D and Koteyko N (2016) Obesity frames and counter-frames in British and German online newspapers. Health DOI: 10.1177/1363459316649764.

Baden D (2015) Shock! Horror! Behind the ethics and evolution of the bad news business. Available at: https://theconversation.com/shock-horror-behind-the-ethics-and-evolutionof-the-bad-news-business-39211 (accessed 16 December, 2016).

Baker P, Gabrielatos C and McEnery T (2013) Discourse analysis and media attitudes: The representation of Islam in the British press. Cambridge: Cambridge University Press.

Bartlett FC (1932) Remembering: A study in experimental and social psychology. Cambridge: Cambridge University Press.

Beckett C (2015) Beyoncé, cute kittens or relentless tragedy? Is good news really news at all? Available at: http://www.theguardian.com/media/2015/feb/01/beyone-cute-kittentragedy-news (accessed 3 June 2016).

Blaney PH (2015) Medical model of mental disorders. The Encyclopedia of Clinical Psychology DOI: 10.1002/9781118625392.wbecp382.

Blood W and Holland K (2004) Risky news, madness and public crisis. Journalism 5(3), 323342.

BNC (2009) What is the BNC? Available at: http://www.natcorp.ox.ac.uk/corpus/ (accessed 1 August 2016).

Braun V and Clarke V (2006) Using thematic analysis in psychology. Qualitative Research in Psychology 3(2), 77-101.

Brown B (2015) Towards a critical understanding of mutuality in mental healthcare: Relationships, power and social capital. Journal of Psychiatric and Mental Health Nursing 22, 829-835.

Brown B (2016) Mutuality in health care: Review, concept analysis and ways forward. Journal of Clinical Nursing 25(9-10), 1464-1475.

Calsamiglia H and López Ferrero C (2003) Role and position of scientific voices: Reported speech in the media. Discourse Studies 5(2), 147-173.

CentreForum Mental Health Commission (2014) The pursuit of happiness: A new ambition for our mental health. Available at: http://www.centreforum.org/assets/pubs/the-pursuit-ofhappiness.pdf (accessed 4 June 2016).

Chamberlain JM (2016) Medicine, risk, discourse and power. London: Routledge.

Childers SE and Harding CM (1990) Gender, premorbid social functioning, and long-term outcome in DSM-III schizophrenia. Schizophrenia Bulletin 16(2), 309-318.

Chong D and Druckman JN (2007) Framing theory. Annual Review of Political Science 10(1), 103-126. 
Conrad P (2005) The shifting engines of medicalization. Journal of Health and Social Behavior 46(1), 3-14.

Corrigan PW, Markowitz FE and Watson AC (2004) Structural levels of mental illness stigma and discrimination. Schizophrenia Bulletin 30(3), 481-491.

Corrigan PW, Watson AC, Gracia G, Slopen N, Rasinski K and Hall LI (2005) Newspaper stories as measures of structural stigma. Psychiatric Services 56(5), 551-556.

Crawford P, Brown B, Nerlich B and Koteyko N (2008) The 'moral careers' of microbes and the rise of the matrons: An analysis of UK national press coverage of methicillin-resistant Staphylococcus aureus (MRSA). Health, Risk and Society 17, 331-347.

Crawford P, Lewis I, Brown B and Manning N (2013) Creative practice as mutual recovery in mental health. Mental Health Review 18(2), 55-64.

Davidson L, Lawless MS and Leary F (2006) Concepts of recovery: Competing or complementary. Current Opinion in Psychiatry 19(6), 619-624.

Deegan G (2003) Discovering recovery. Psychiatric Rehabilitation Journal 26(4), 368-376.

Department of Health (2001) The journey to recovery: The government's vision for mental health care. London: Department of Health.

Department of Health (2009) Working our way to better mental health: A framework for action. London: Department of Health.

Department of Health (2011) No health without mental health: A cross-government mental health outcomes strategy for people of all ages. London: Department of Health.

Department of Health (2011) No health without mental health: Implementation framework. London: Department of Health.

Duguid A (2010) Newspaper discourse informalisation: A diachronic comparison from keywords. Corpora 5(2), 109-138.

Elliott L (2011) Global financial crisis: Five key stages 2007-2011. Available at: https://www.theguardian.com/business/2011/aug/07/global-financial-crisis-key-stages (accessed 17 December, 2016).

Entman R (1993) Framing: Toward clarification of a fractured paradigm. Journal of Communication 43(3): 51-58.

Gamson WA (1992) Talking politics. New York: Cambridge.

Gamson WA and Modigliani A (1989) Media discourse and public opinion on nuclear power: A constructionist approach. American Journal of Sociology 95(1), 1-37.

Glasgow SM (2012) The politics of self-craft: Expert patients and the public health management of chronic disease. SAGE Open, 1-11.

Harcup T and O'Neill D (2016) What is news? News values revisited (again). Journalism Studies DOI: 10.1080/1461670X.2016.1150193.

Harper D and Speed E (2012) Uncovering recovery: The rise of recovery and resilience. Studies in Social Justice 6(1), 9-25.

Hofmann B (2016) Medicalization and overdiagnosis: different but alike. Medical Health Care and Philosophy DOI 10.1007/s11019-016-9693-6.

Holley LC, Tavassoli KY and Stromwall LK (2016) Mental illness discrimination in mental health treatment programs: Intersections of race, ethnicity, and sexual orientation. Community Mental Health Journal 52(3), 311-322.

Jacob S, Munro I, Taylor BJ and Griffiths D (in press) Mental health recovery: A review of the peer-reviewed published literature, The Collegian DOI: 10.1016/j.colegn.2015.08.001. 
Jacobson $\mathrm{N}$ and Greenley D (2001) What is recovery? A conceptual model and explication. Psychiatric Services 52, 482-485.

Johnson JMQ and Miller B (2016) When women 'snap': The use of mental illness to contextualize women's acts of violence in contemporary popular media. Women's Studies in Communication 39(2), 211-227.

Kelly B, Hornik R, Romantan A, Schwartz JS, Armstrong K, DeMichele A and Hull S (2010) Cancer information scanning and seeking in the general population. Journal of Health Communication 5, 734-753.

Kenez S, O'Halloran P and Liamputtong P (2015) The portrayal of mental health in Australian daily newspapers. Australian and New Zealand Journal of Public Health 39(6), 513-517.

Klin A and Lemish D (2008) Mental disorders stigma in the media: Review of studies on production, content, and influences. Journal of Health Communication 13, 434-449.

legislation.gov.uk (2007) Mental Health Act 2007. Available at: http://www.legislation.gov.uk/ukpga/2007/12/contents (accessed 4 June 2016).

Lewis L, Spandler H, Tew J, Ecclestone K and Croft H (2016) Mutuality, wellbeing and mental health recovery: Exploring the roles of creative arts adult community learning and participatory arts initiatives. Available at:

http://www.wlv.ac.uk/media/departments/research/documents/SUMMARY-REPORTFINAL-VERSION.pdf (accessed 10 August, 2016).

Lupton D (1999) Editorial: Health, illness and medicine in the media. Health (London) 3, 259262.

Matthes J (2009) What's in a frame? A content analysis of media-framing studies in the world's leading communication journals, 1990-2005. Journalism \& Mass Communication Quarterly 86, 349-367.

McCombs ME and Shaw DL (1972) The agenda-setting function of mass media. Public opinion quarterly 36(2), 176-187.

McGinty EE, Kennedy-Hendricks A, Choksy S and Barry CL (2016) Trends in news media coverage of mental illness in the United States: 1995-2014. Health Affairs 35(6), 11211129.

McKeown T (1976) The modern rise of population. London: Edward Arnold.

Meadows R (2008) The rights and duties of the sleeper. AMA Journal of Ethics 10(9), 585-588.

Miller P (2016) Funding for arts at stand still or cut in new Scottish Budget. Available at: http://www.heraldscotland.com/news/14969884.Funding_for_arts_at_stand_still_or_cut in_new_Scottish_Budget/ (accessed 17 December, 2016).

Montgomery M (2007) The discourse of broadcast news: A linguistic approach. Abingdon: Routledge.

Olufowote JO and Matusitz J (2016) 'How dark a world it is ... where mental health is poorly treated": Mental illness frames in sermons given after the Sandy Hook shootings. Health Communication DOI: 10.1080/10410236.2015.1089458.

Ortiz SE, Kawachi I and Boyce AM (2016) The medicalization of obesity, bariatric surgery, and population health. Health DOI: 10.1177/1363459316660858.

Pinquart M and Sörensen S (2003) Differences between caregivers and noncaregivers in psychological health and physical health: A meta-analysis. Psychology and Aging 18(2), 250-267. 
Pountney D (2015) Austerity and the arts: The hidden cuts that are bad for our cultural health. Available at: https://www.theguardian.com/music/2015/apr/21/david-pountney-artsfunding-bad-for-our-cultural-health (accessed 17 December, 2016).

Riffe D (2004) An editorial comment. Journalism \& Mass Communication Quarterly 81(1), 2-3. Rowe D (2005) Fourth estate or fan club? Sports journalism engages the popular. In S., Allan (Ed.), Journalism: Critical issues (pp. 125-136) Maidenhead: Open University Press.

Scheid TL (2016) An institutional analysis of public sector mental health in the postdeinstitutionalization era. Advances in Medical Sociology 17, 63-87.

Scott M (2016) WordSmith Tools version 7. Stroud: Lexical Analysis Software.

Sinclair J (1991) Corpus, concordance, collocation. Oxford: Oxford University Press.

Smith-Merry J and Gillespie J (2016) Embodying policy-making in mental health: The implementation of Partners in Recovery. Health Sociology Review 25(2), 187-201.

Soroka S, Farnsworth S, Lawlor A and Young L (2013) Mass media and policy-making. In E., Araral, S., Fritzen, M., Howlett, M., Ramesh, \& X., Wu (Eds.), Routledge Handbook of Public Policy (pp. 204-215). London: Routledge.

Stacey G, Felton A, Morgan A, Stickley T, Willis M, Diamond B, Houghton P, Johnson B and Dumenya J (2016) A critical narrative analysis of shared decision-making in acute inpatient mental health care. Journal of Interprofessional Care 30(1), 35-41.

Staricoff RL (2004) Arts in health: A review of the medical literature. London: Arts Council England.

Stefanik-Sidener K (2013) Nature, nurture, or that fast food hamburger: Media framing of diabetes in the New York Times from 2000 to 2010. Health Communication 28(4), 351358.

Stickley T, Higgins A, Meade O, Sitvast J, Doyle L, Ellilä H, Jormfeldt H, Keogh B, Lahti M, Skärsäter I, Vuokila-Oikkonen P and Kilkku N (2016) From the rhetoric to the real: A critical review of how the concepts of recovery and social inclusion may inform mental health nurse advanced level curricula - The eMenthe project. Nurse Education Today 37, $155-163$.

Taibi C (2015) As the media reaches 'peak negativity,' A rallying cry to focus on solutions. Available at: http://www.huffingtonpost.com/2015/02/19/negative-news-bbc-charliebeckett-positive-good-stories_n_6706128.html (accessed 16 December, 2016).

Tew J (2013) Recovery capital: What enables a sustainable recovery from mental health difficulties? European Journal of Social Work 16(3), 360-374.

Thornicroft A, Goulden R, Shefer G, Rhydderch D, Rose D, Williams P, Thornicroft G and Henderson C (2013) Newspaper coverage of mental illness in England 2008-2011. The British Journal of Psychiatry 202, s64-s69.

Thornton JA and Wahl OF (1996) Impact of a newspaper article on attitudes toward mental illness. Journal of Community Psychology 24, 17-25.

Touri M and Koteyko N (2015) Using corpus linguistic software in the extraction of news frames: Towards a dynamic process of frame analysis in journalistic texts. International Journal of Research Methodology 18(6), 601-616.

van Gorp B (2007) The constructionist approach to framing: bringing culture back in. Journal of Communication 57, 60-78.

van Gorp B (2010) Strategies to take subjectivity out of framing analysis. In P., D'Angelo, \& J., Kuypers (Eds.), Doing news framing analysis: Empirical and theoretical perspectives (pp. 84-109). New York: Routledge. 
van Gorp B and Vercruysse T (2012) Frames and counter-frames giving meaning to dementia: A framing analysis of media content. Social Science and Medicine 74, 1274-1281.

van Leeuwen T (2008) Discourse and practice. Oxford: Oxford University Press.

Whitley R, Adeponle A and Miller AR (2015) Comparing gendered and generic representations of mental illness in Canadian newspapers: An exploration of the chivalry hypothesis. Social Psychiatry and Psychiatric Epidemiology 50, 325-333.

Whitley R and Berry S (2013) Trends in newspaper coverage of mental illness in Canada: 20052010. Canadian Journal of Psychiatry 58(2), 107-112.

Whitley R and Drake RE (2010) Recovery: A dimensional approach. Psychiatric Services 61, 1248-1250. 
Table 1. Keywords in decreasing order of keyness (log-likelihood value).

\begin{tabular}{|c|c|c|c|}
\hline MENTAL (10535.74) & NEW (1355.67) & THING (806.6) & OPPORTUNITY (587.28) \\
\hline HEALTH (10006.82) & COME (1342.96) & TELL (801.09) & LIVE (582.54) \\
\hline PEOPLE (8376.66) & EXPERIENCE (1330.22) & START (784.91) & MEMBER (581.07) \\
\hline SAY (7172.37) & ISSUE (1289.09) & SESSION (756.01) & IMPROVE (578.07) \\
\hline HELP (4768.01) & YOUNG (1260.19) & HOPE (755.08) & CARER (561.24) \\
\hline ART (4273.16) & PROVIDE (1152.56) & TALK (748.57) & STAFF (546.32) \\
\hline WORK (2708.57) & DAY (1136.84) & THERAPY (733.52) & OPEN (542.73) \\
\hline SUPPORT (2568.96) & CARE (1130.61) & RAISE (719.59) & RUN (540.67) \\
\hline SERVICE (2488.19) & CENTRE (1102.28) & WELLBEING (713.91) & LEARN (528.68) \\
\hline PROBLEM (2361.33) & DEMENTIA (1101.51) & STIGMA (700.04) & $\operatorname{ADD}(528.01)$ \\
\hline GROUP (2045.72) & THINK (1099.07) & FUND (689.89) & MUSIC (518.35) \\
\hline PATIENT (2032.92) & MAKE (1059.82) & AIM (688.47) & MEET (515.78) \\
\hline ILLNESS (1859.01) & USE (1055.72) & LOCAL (686.21) & PROGRAMME (513.78) \\
\hline DEPRESSION (1841.78) & NHS (1038.52) & ARTIST (670.47) & RECOVERY (495.64) \\
\hline CHARITY (1788.48) & EVENT (1021.76) & AWARENESS (668.99) & CHANGE (486.28) \\
\hline LIFE (1746.27) & WAY (976.28) & PLACE (659.9) & ENCOURAGE (481.72) \\
\hline PROJECT (1700.19) & TIME (968.78) & AWARD (656.91) & TREATMENT (473.36) \\
\hline FEEL (1641.08) & KNOW (964.61) & INVOLVE (653.93) & TEAM (469.92) \\
\hline NEED (1616.76) & OFFER (937.47) & ANXIETY (653.4) & POSITIVE (466.34) \\
\hline HOSPITAL (1505.66) & TRUST (928.66) & SOCIAL (645.74) & SUICIDE (463.7) \\
\hline COMMUNITY (1505.56) & CREATIVE (879.62) & FRIEND (604.95) & TRY (463.45) \\
\hline INCLUDE (1476.77) & ACTIVITY (857.94) & CONDITION (601.5) & RECEIVE (456.79) \\
\hline DISORDER (1408.78) & EXHIBITION (856.88) & WORKSHOP (595.27) & BELIEVE (444.65) \\
\hline WANT (1371.8) & FAMILY (836.45) & SCHOOL (589.86) & COUNCIL (444.11) \\
\hline SUFFER (1361.13) & VOLUNTEER (821.49) & CHILD (587.97) & STRESS (442.92) \\
\hline
\end{tabular}


Table 2 Frames.

\begin{tabular}{|c|c|c|c|}
\hline & Recovery & Stigma & Economy \\
\hline Problem definition & $\begin{array}{l}\text { Recovery is possible. Mental } \\
\text { illness can be treated just } \\
\text { like physical illness. } \\
\text { Indicative keywords: } \\
\text { DISORDER, ILLNESS, } \\
\text { PATIENT, RECOVERY, } \\
\text { THERAPY, TREATMENT, } \\
\text { WELLBEING }\end{array}$ & $\begin{array}{l}\text { Mental illness is still a taboo } \\
\text { and mentally ill people face } \\
\text { stigma, discrimination and } \\
\text { social exclusion. } \\
\text { Indicative keywords: } \\
\text { AWARENESS, RAISE, STIGMA }\end{array}$ & $\begin{array}{l}\text { The cost of mental illness } \\
\text { is high and/or growing. } \\
\text { Indicative keywords: } \\
\text { CHARITY, COUNCIL, FUND, } \\
\text { OFFER, PROGRAMME, } \\
\text { SERVICE, SESSION }\end{array}$ \\
\hline Causes & Not discussed. $^{6}$ & $\begin{array}{l}\text { - Entertainment venues } \\
\text { reinforce stigma; } \\
\text { - Persistent superstitions; } \\
\text { - Misinformation and lack of } \\
\text { information }\end{array}$ & $\begin{array}{l}\text { - Productivity lost to } \\
\text { mental illness; } \\
\text { - Employment allowance } \\
\text { claims by mentally ill } \\
\text { individuals }\end{array}$ \\
\hline Consequences & Not discussed. & $\begin{array}{l}\text { - Stigma inhibits funding for } \\
\text { mental health services; } \\
\text { - Stigma inhibits disclosing } \\
\text { condition and seeking help }\end{array}$ & Not discussed. \\
\hline Solutions & $\begin{array}{l}\text { - Arts participation as a form } \\
\text { of therapy; } \\
\text { - Arts participation as a } \\
\text { complement to medication; } \\
\text { - Arts participation as an } \\
\text { alternative to medication; } \\
\text { - Offer (more) social } \\
\text { prescribing schemes; } \\
\text { - Train care workers in } \\
\text { creative arts techniques }\end{array}$ & $\begin{array}{l}\text { - Raise awareness about } \\
\text { mental illness through arts } \\
\text { participation }\end{array}$ & $\begin{array}{l}\text { - Arts participation to aid } \\
\text { work transition; } \\
\text { - Arts participation for } \\
\text { prevention (more cost } \\
\text { efficient than treatment) }\end{array}$ \\
\hline Moral evaluations & $\begin{array}{l}\text { Society still views mentally } \\
\text { ill individuals in negative } \\
\text { terms. }\end{array}$ & Not discussed. & Not discussed. \\
\hline
\end{tabular}

\footnotetext{
${ }^{6}$ It is possible that a frame does not elaborate all elements (problem definition, causes, etc.) (Entman, 1993) which is denoted with 'Not discussed'.
} 